Synthesis of Natural

Products and

Potential Drugs

\section{Synthesis of a Key Intermediate of Omarigliptin}

\section{Key words}

omarigliptin

DPP-4 inhibitor

Meerwein-

Ponndorf-Verley reduction

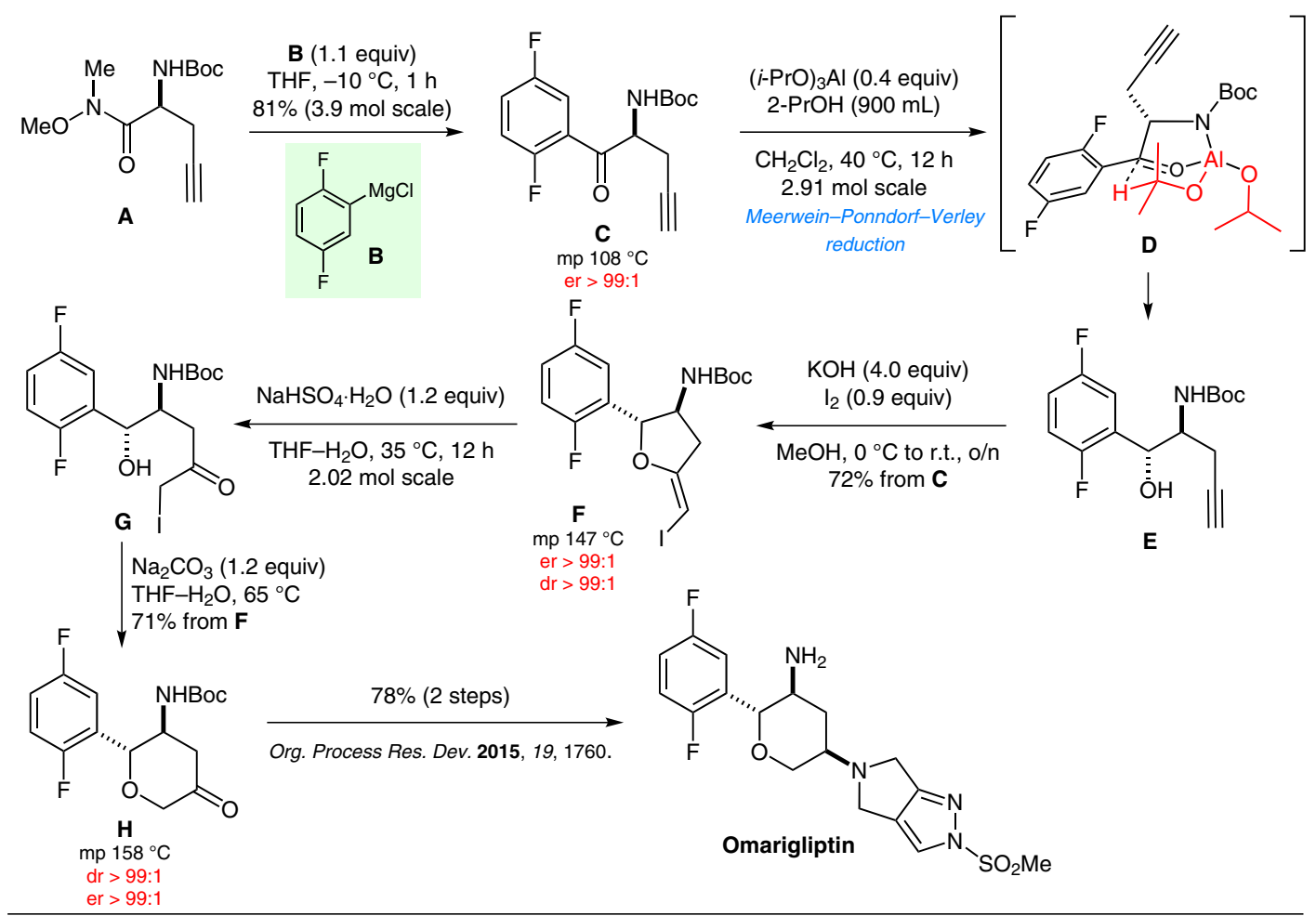

Synthesis of fragment $\mathbf{A}$ :<smiles></smiles>

$\mathrm{NaOH}$ (1.5 equiv) DMF- $\mathrm{H}_{2} \mathrm{O},-10^{\circ} \mathrm{C}, 0.5 \mathrm{~h}$

3-chloro-1-propyne (1.5 equiv) $98 \%$ (3.75 mol scale)
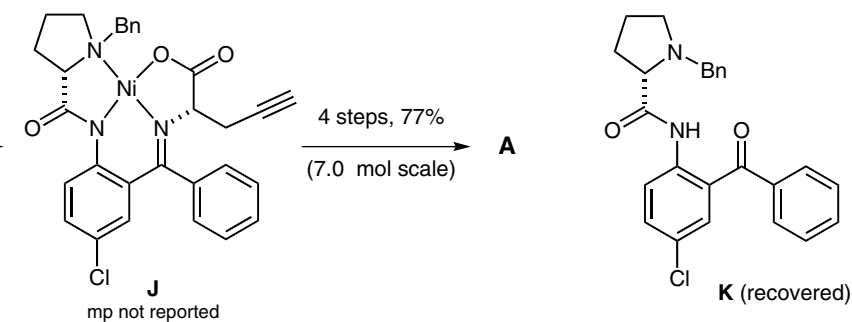

asymmetric enolate alkylation

iodoetherification

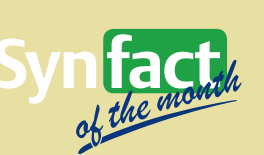

Significance: Wang and co-workers describe a kilogram-scale asymmetric synthesis of intermediate $\mathbf{H}$ en route to omarigliptin, a DPP-4 inhibitor that is of interest for the treatment of diabetes. The key steps in the synthesis depicted are (1) the diastereoselective substrate-controlled MeerweinPonndorf-Verley reduction of $\alpha$-aminoketone $\mathbf{C}$ and (2) the stereoselective intramolecular 5-exodig iodoetherification of alkynol E. SYNFACTS Contributors: Philip Kocienski

Synfacts 2017, 13(03), 0225 Published online: 15.02.2017 Dol: 10.1055/s-0036-1590076; Reg-No.: K00517SF
Comment: Synthesis of $\mathbf{A}$ began with the asymmetric $\alpha$-alkylation of nickel(II) complex I with 3-chloro-1-propyne. The choice of solvent and temperature was critical to achieve a reproducible conversion and high stereoselectivity for this alkylation. Best results were obtained using sodium hydroxide in DMF at $-10^{\circ} \mathrm{C}$. At the end of the reaction, water was added to the reaction mixture, and product $\mathbf{J}$ crystallized out from the aqueous media. 